\title{
Recurrence of Gastric Masses in a Neonate with Congenital Myotonic Dystrophy
}

\author{
Pooja Shivananda Siddhi ${ }^{1} \cdot$ Imogen Storey $^{1}$
}

Received: 30 October 2017 / Accepted: 10 January 2018 /Published online: 31 January 2018

(C) Dr. K C Chaudhuri Foundation 2018

A term female baby was born to a multiparous mother with myotonic dystrophy. The baby required a brief period of ventilation and was slowly commenced on enteral feeds. Genetic tests confirmed a diagnosis of Congenital Myotonic Dystrophy (CMD).

A diagnosis of gastro-esophageal reflux was made following failure to tolerate full volume feeds. A trial of oral Gaviscon was commenced. Routine clinical examination revealed a non-tender firm mass in the left sub-costal area. Abdominal x-ray showed a mass in the stomach bubble suggestive of Gaviscon bezoar (Fig. 1). There were no clinical signs of bowel obstruction [1]. Gaviscon was stopped. Feed intolerance persisted and Carobel was introduced. This resulted in a similar mass noted clinically and on imaging. Discontinuation of the thickener resulted in resolution of the bezoar.

Later attempts at establishing feeds via naso-jejunal tube were unsuccessful. Gastrostomy was inserted.

Feed intolerance in infants with CMD is well documented. Gastric paresis due to smooth muscle abnormalities leads to delayed gastric emptying. Gaviscon infant unlike adult gaviscon does not contain bicarbonate; hence instead of forming a raft, it thickens the stomach content. The evidence base for use of Gaviscon in infants with neuromuscular disorders is limited.

Thus to conclude, maturation arrest of smooth muscle in patients with CMD leads to transient gastrointestinal dysmotility [2-5]. Feed thickeners should be used with cau-

Pooja Shivananda Siddhi

p.siddhi@nhs.net

1 Birmingham Heartlands Hospital, Bordesley Green, B9 5SS, Birmingham, UK

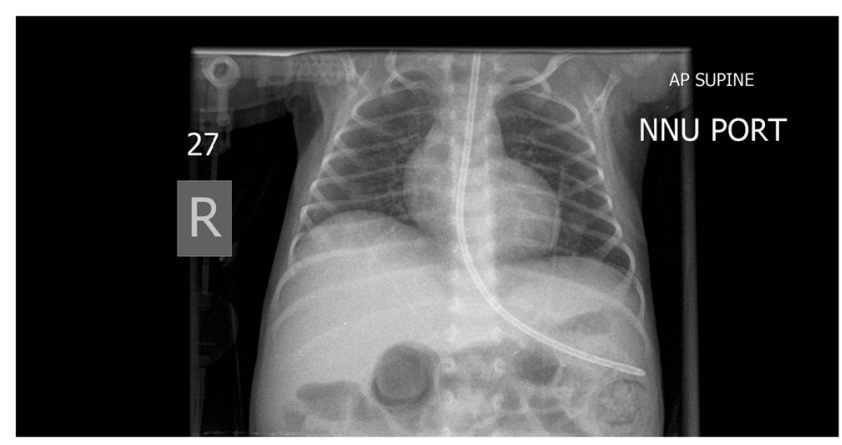

Fig. 1 Antero-Posterior view of the chest and upper part of abdomen showing a white homogenous lesion in the left subcostal region and a naso-gastric tube in the stomach

tion in infants with neuro-muscular disorders. The importance of good clinical examination is highlighted in this case.

Author Contributions PSS gathered the case details, literature search and wrote the manuscript. IS contributed in correcting the manuscript and will act as guarantor for this paper.

\section{Compliance with Ethical Standards}

Conflict of Interest None.

\section{References}

1. Hewitt GJ, Benham ES. A complication of Gaviscon in a neonate'the Gavisconoma'. Aust Paediatr J. 1976;12:47-8.

2. Matsui K, Yamashita S, Shibasaki J, Watanabe T. Bethanechol for neonatal transient gastrointestinal dismotility in two cases of congenital myotonic dystrophy. No To Hattatsu. 2007;39:304-8.

3. Bodensteiner JB, Grunow JE. Gastroparesis in neonatal myotonic dystrophy. Muscle Nerve. 1984;7:486-7.

4. Sarnat HB, O'Connor T, Byrne PA. Clinical effects of myotonic dystrophy on pregnancy and the neonate. Arch Neurol. 1976;33: 459-65.

5. Sorbie AL, Symon DN, Stockdale EJ. Gaviscon bezoars. Arch Dis Child. 1984;59:905-6. 